\title{
ЛОКАЛЬНИЙ МАКСВЕЛЛІВСЬКИЙ РОЗПОДІЛ У РІДИНАХ
}

\author{
Л.А. БУЛАВІН, Ю.Ф. ЗАБАШТА
}

УДК 544.273

(C) 2012
Київський національний університет ім. Тараса Шевченка, фізичний факультет (Вул. Володимирсъка, 64, Київ МСП 01601; e-mail: zabashta@mail. univ. kiev. ua)
Розглянуто просторовий та часовий інтервали, що слугують для рідин масштабами в гідродинаміці. Ці інтервали ототожнюються із розміром області, де встановлюється локальний максвеллівський розподіл, і часом, за який цей розподіл встановлюється. Показано, що максвеллівський розподіл виникає у рідинах завдяки взаємодії між локалізованими тепловими коливаннями частинок рідини. Для просторового та часового масштабів гідродинаміки отримано оцінки - відповідно, 100 нм та $10^{-10} \mathrm{c}$.

\section{1. Вступ}

Як відомо [1], в гідродинаміці рідина розглядається як суцільне середовище. Відповідно стан рідини визначається полями фізичних величин; одним 3 цих полів є температурне поле $T(\mathbf{r}, t)$, де $\mathbf{r}=x, y, z-$ радіус-вектор точки простору, зайнятого рідиною, $t$ час. Поведінку рідини описують, використовуючи похідні згаданих фізичних величин по просторових координатах та часові. Відповідно в розгляд вводяться нескінченно малі величини: просторові $d x, d y, d z$ та часовий $d t$ нескінченно малі інтервали. Вводиться також поняття про математичний нескінченно малий об'єм - область, що є околом точки $r$ і має об'єм $d \mathbf{r}=d x d y d z$.

Зрозуміло, що поняття про нескінченно малу величину є математичною абстракцією і в дійсності нескінченно малим інтервалам відповідають скінченні інтервали: просторовий $\Delta r$ і часовий $\Delta t$. Останні відіграють ролі просторового та часового масштабів у гідродинаміці.

Не існує також математичного нескінченно малого об'єму - в дійсності йому відповідає область із скінченним об'ємом $\Delta r^{3}$, яку називають фізичним нескінченно малим об'ємом (ФНМО) [1].

Таким чином, температура $T(\mathbf{r}, t)$, яка приписується області $d \mathbf{r}$ фактично є температурою ФМНО, який оточує точку r. Про температуру ж області, як відомо [2], можна говорити, якщо в цій області встановлюється максвеллівський розподіл по швид- костях теплового руху частинок. Його називають локальним.

Очевидно, що скінченний розмір ФНМО накладає обмеження на верхню межу швидкостей теплового руху частинок, які містяться в даній області. Тому в даному випадку можна говорити лише про неповний - наближений максвеллівський розподіл. Отже, $\Delta r$ - це лінійний розмір області, в якій встановлюється згаданий розподіл. 3 тієї ж причини $\Delta t-$ це час, за який вказаний розподіл встановлюється.

Мета даної роботи - запропонувати механізм встановлення локального максвеллівського розподілу в рідинах і на основі запропонованого механізму визначити порядок величин $\Delta r$ і $\Delta t$. Як відомо авторам, це питання раніше в літературі не обговорювалось.

\section{2. Розрахункова модель}

$\mathrm{y}$ даній статті розглядатимемо систему $N$ однакових безструктурних частинок. Власним об'ємом частинки вважатимемо об'єм $v_{0}$, що припадає на частинку, у випадку, коли система знаходиться в кристалічному стані. Розмір частники $а$ визначатимемо за виразом

$a=v_{0}^{1 / 3}$.

У випадку, коли система не знаходиться у кристалічному стані, об'єм, що припадає на одну частинку, позначатимемо через $v_{1}$. Введемо в розгляд характерний лінійний розмір $u$, який визначатимемо формулою

$v_{1}^{1 / 3}-a=u$.

Відповідатимуть обом згаданим розмірам характерні часові інтервали $\tau_{0}$ та $\tau_{1}$, які розраховуватимемо за формулами

$\tau_{0}=a / c$

$\tau_{1}=u / c$,

де $c$ - деяка характерна швидкість. 


\section{3. Малий параметр у фізиці рідин}

Порівняно з іншими фізичними системами, мабуть, 3 найбільшою повнотою теорію встановлення локального максвеллівського розподілу розроблено для розрідженого газу [2]. Саме ця обставина спонукає нас звернутися до цієї теорії і нагадати деякі її результати, сподіваючись використати їх у випадку рідин.

Для розрідженого газу справедливою є така ієрархія просторових масштабів:

$a \ll u \ll l$,

де $l$ - середня довжина вільного пробігу частинки, що розраховується за формулою

$l \sim u(u / a)^{2}$.

Просторовій ієрархї (5) відповідає часова ієрархія

$\tau_{0} \ll \tau_{1} \ll \tau$,

де $\tau$ - середній час вільного пробігу частинки, що розраховується за формулою

$\tau \sim l / c$,

де $c$ - середня теплова швидкість частинок.

Локальний максвеллівський розподіл, як відомо [2], встановлюється на довжині вільного пробігу, а час його встановлення дорівнює часові вільного пробігу. Таким чином, у випадку розрідженого газу для розміру $\Delta r$ ФМНО та часу $\Delta t$ встановлення у ФМНО максвеллівського розподілу маємо

$a \ll u \ll \Delta r$

$\tau_{0} \ll \tau_{1} \ll \Delta t$

$\Delta r \sim u(u / a)^{2}$

$\Delta t \sim \tau_{1}(u / a)^{2}$

Як видно із формул (9)-(12), для розрідженого газу існує малий параметр

$\beta=a / u$,

який, власне, і визначає існування обох згаданих ієрархій. Дійсно, підставивши рівність (13) у формули (9)-(12), замість співвідношень (9), (10), отримаємо

$\beta^{3} \ll \beta^{2} \ll 1$.
При цьому рівності (9)-(12) набувають вигляду

$\Delta r \sim u \beta^{-2}$

$\Delta t \sim \tau_{1} \beta^{-2}$

Чи існує для рідин малий параметр, за допомогою якого можна було б вибудувати просторову та часову ієрархї за аналогією із розрідженим газом? У літературі [3] існування такого параметра заперечується. На нашу ж думку, такий параметр існує.

Дійсно, на відміну від розрідженого газу для рідини просторова та часова ієрархї мають вигляд

$u \ll a \ll \Delta r$,

$\tau_{1} \ll \tau_{0} \ll \Delta t$

$\mathrm{У}$ виразах (17),(18) ми зустрічаємось із малим параметром

$\phi=u / a$.

Отже, для рідини все-таки можливо ввести малий параметр. Але чи виконуються при цьому співвідношення, аналогічні співвідношенням, які властиві розрідженому газу, а саме:

$\Delta r \sim a \phi^{-2}$,

$\Delta t \sim \tau_{0} \phi^{-2}$

Наступні міркування, на нашу думку, дають ствердну відповідь на це запитання.

\section{4. Механізм встановлення локального максвеллівського розподілу в рідині}

Як відомо [4], в рідинах реалізується два типи теплового руху частинок: коливання та випадкові блукання. Останній тип являє собою послідовність елементарних переміщень, що в середньому відбуваються через проміжок часу, названий часом осідлого життя:

$\tau^{\prime}=\tau_{0}^{\prime} \exp \left(\frac{\Delta F}{k_{\mathrm{B}} T}\right)$

де $k_{\mathrm{B}}$ - стала Больцмана, $\Delta F$ - бар'єр вільної енергії, який долається частинкою при кожному елементарному переміщенні; величину $\tau_{0}^{\prime}$ ототожнено із періодом теплових коливань частинки. 
Для наших міркувань принципове значення має той факт, що в формулу (22) входить температура. 3 цього факту випливає очевидний висновок: для того, щоб відбулось елементарне переміщення даної частинки, в ï околі мусить встановитись максвеллівський розподіл. Таке твердження вимагає виконання нерівності

$\Delta t \ll \tau^{\prime}$.

Існування цієї нерівності означає, що випадкові блукання ніякої участі у встановленні максвеллівського розподілу не беруть i, отже, згаданий розподіл встановлюється виключно за рахунок взаємодії між тепловими коливаннями. Відповідно величина $c \mathrm{\epsilon}$ швидкістю поширення коливального збудження, яку можна ототожнити із швидкістю поширення звука.

Завдяки нерівності (23) можна вважати, що протягом часового відрізка $\tau^{\prime}$ рівноважні положення частинок не змінюються, тобто, рідину, протягом цього часу $\tau^{\prime}$ можна розглядати як квазікристал, використовуючи методи фізики твердого тіла [5].

Позначимо через $\mathbf{R}=\left\{R_{1}, R_{2}, \ldots, R_{3 N}\right\}-3 N$ вимірний вектор, компоненти $R_{j}$ якого $є$ координатами частинок. Вочевидь, вектор $\mathbf{R}$ визначає конфігурацію системи - розташування в просторі частинок, що входять до її складу. Нехай у випадку, коли система знаходиться у кристалічному стані, конфігурація рівноважних положень частинок визначається вектором $\mathbf{R}_{0}$. Введемо позначення $E(\mathbf{R})$ для потенціальної енергії та $\mathbf{S}=\mathbf{R}-\mathbf{R}_{0}$ для зміщення частинок. Розкладемо $E(\mathbf{R})$ в ряд по степенях зміщень:

$E(\mathbf{R})=E\left(\mathbf{R}_{0}\right)+\mathbf{Q S}+\mathbf{B S S}+\mathbf{G S S S}+\ldots$,

де прийнято позначення

$\mathbf{Q}=\left\{q_{j}\right\}=\left.\frac{\partial E}{\partial \mathbf{S}}\right|_{\mathbf{R}=\mathbf{R}_{0}}$,

$\mathbf{B}=\left\{b_{j k}\right\}=\left.\frac{1}{2} \frac{\partial^{2} E}{\partial \mathbf{S}^{2}}\right|_{\mathbf{R}=\mathbf{R}_{0}}$,

$\mathbf{G}=\left\{g_{j k l}\right\}=\left.\frac{1}{3 !} \frac{\partial^{3} E}{\partial \mathbf{S}^{3}}\right|_{\mathbf{R}=\mathbf{R}_{0}}$.

Запишемо зміщення $\mathbf{S}$ у вигляді суми:

$\mathbf{S}=\mathbf{U}+\mathbf{W}$

де $\mathbf{U}=\left\{u_{j}\right\}-$ різниця між координатами, що визначають рівноважні положення частинок у кристалічному та аморфному станах ("статичне" зміщення), $\mathbf{W}=\left\{w_{j}\right\}-$ зміщення, пов'язане із тепловими коливаннями частинок (коливальне зміщення). Прикметник "статичне" взято в лапки, щоб підкреслити умовність цього терміну, бо йдеться фактично не про абсолютну незмінність рівноважних положень частинок, а лише протягом часу $\tau^{\prime}$.

Підставляючи вираз (26) у формулу (24) і обмежуючись доданками другої степені по $\mathbf{W}$, отримуємо

$H=H_{0}+H^{\prime}$,

де позначено

$H=E(\mathbf{R})-\left(E\left(\mathbf{R}_{0}\right)+E_{1}+E_{2}\right)$,

$E_{1}=\mathbf{Q} \cdot \mathbf{W}+\mathbf{B}: \mathbf{U U}+\mathbf{G U U U}+\ldots$

$E_{2}=\mathbf{Q} \cdot \mathbf{W}+\mathbf{B}: \mathbf{U W}+\mathbf{G}: \mathbf{U U W}+$

$+\mathbf{G}: \mathbf{U W U}+\mathbf{G}: \mathbf{W U U}+\ldots$,

$H_{0}=\mathbf{B}: \mathbf{W} \mathbf{W}$,

$H^{\prime}=\mathbf{G}: \mathbf{U W W}+\mathbf{G}: \mathbf{W U W}+\mathbf{G}: \mathbf{W} \mathbf{W} \mathbf{U}$

Згідно з рівностями (28), (29) для рідини відлік енергії теплових коливань провадиться від значення $E\left(\mathbf{R}_{0}\right)+E_{1}$.

Як це видно із виразу (31), величина $H_{0}$ - це енергія теплових коливань кристала в гармонічному наближенні.

Згідно з формулами (30) та (32) величини $E_{2}$ та $H^{\prime}$ $\epsilon$, відповідно, енергією взаємодії теплових коливань із "статичними" зміщеннями в першому та другому порядках наближення по $\mathbf{W}$.

Оскільки кожен доданок суми (30) є лінійним відносно $\mathbf{W}$, то очевидно, що величина $E_{2}$ не описує взаємодії між тепловими коливаннями. В даному наближенні така можливість залишається тільки за величиною $H^{\prime}$.

Маючи на увазі відому оцінку [4]:

$g \sim b / a$

приходимо до висновку про існування малого параметра в фізиці рідин:

$\phi=\frac{H^{\prime}}{H_{0}} \sim u / a$.

Як це видно із виразів (27), (32), за їх допомогою задача про коливний рух частинок рідини зведена до 
класичної схеми теорії збурень: ми маємо незбурений гамільтоніан $H_{0}$ та малу поправку до нього - збурення $H^{\prime}$. Згідно з цією теорією [3], завдяки збуренню виникає релаксаційний процес, що характеризується часом релаксації:

$\theta=\theta_{0} \phi^{-2}$

де $\theta_{0}$ - часовий масштаб для даного процесу.

Вибір часового масштабу для того чи іншого релаксаційного процесу грунтується на часовій ієрархії. Так, нехай ми маємо, наприклад, на увазі процес, що характеризується часом релаксації $\theta=\Delta t$ із виразу (21). Нерівність $\tau_{0} \ll \Delta t$ спонукує нас розглядати нульове наближення по малому параметру $\tau_{0} / \Delta t$. За такого наближення вважається, що протягом часового інтервалу $\tau_{0}$ фізичні параметри не зазнають ніяких змін. Але якраз ця особливість властива часовому інтервалу, що його приймають за масштаб. Отже, в даному випадку справедливою виявляється рівність $\theta_{0}=\tau_{0}$, так що формула (35) збігається із формулою (21).

Із такого збігу випливає, що у випадку, коли максвеллівський розподіл встановлюється завдяки взаємодії між тепловими коливаннями, справедлива i формула (20). Це означає, що згаданий максвеллівський розподіл встановлюється в області із розміром $\Delta r$, який визначається за цією формулою.

Таким чином, наші попередні припущення щодо можливості застосування формул (20), (21) для опису поведінки рідин, на нашу думку, можна вважати підтвердженими.

\section{5. Числові оцінки}

Увівши позначення $\Delta v=v_{1}-v_{0}$, із формул (1)-(3), (19) 19) маємо

$\phi=\frac{1}{3} \frac{\Delta v}{v_{0}}$,

де відношення $\frac{\Delta v}{v_{0}}$ відповідає відносній зміні об'єму при плавленні системи, коли та знаходиться в кристалічному стані. Розрахуємо значення величин $\Delta r$ і $\Delta t$ для рідкого аргону. Згідно з довідниковими даними маємо $v_{0}=43 \cdot 10^{-30} \mathrm{~m}^{3}, \frac{\Delta v}{v_{0}}=0,15 \mathrm{c} \sim 10^{3} \mathrm{M} / \mathrm{c}$.

Використовуючи формули (1)-(4), (20), (31), (36) та наведені числові дані, отримуємо $\Delta r \sim 10^{-7} \mathrm{M}$, $\Delta t \sim 10^{-10}$ c.

\section{6. Локалізація високочастотних коливань у рідині}

Той факт, що максвеллівський розподіл встановлюється в деякій області з очевидністю означає, що й коливання, взаємодія між якими приводить до встановлення локального максвеллівського розподілу, локалізовані у цій же області.

Зрозуміло також, що хвильовий вектор $\mathbf{k}$ коливань, які беруть участь у цьому процесі, мусить задовольняти умову

$k \Delta r \gg \pi$.

Називатимемо коливання, що відповідають цій умові, високочастотними. Коливання, що задовольняють нерівність

$k \Delta r \ll \pi$,

називатимемо низькочастотними.

Отже, в прийнятих термінах ми можемо говорити, що на відміну від низькочастотних - делокалізованих, високочастотні теплові коливання в рідині локалізовані в областях із розміром $\Delta r$.

Запишемо коливальне зміщення у вигляді суми нормальних коливань кристала:

$w_{j}=\sum_{k} w_{j k} \exp \left(-i \omega_{k} t\right) \exp (i \mathbf{k r})$.

де $\omega_{k}$ - власні частоти кристала, а компоненти $k_{j}$ хвильового вектора набувають значення $k_{j}=\pi p / L$, де $L$ - розмір системи, $p$ - цілі числа.

Розкладемо "статичне" зміщення у тригонометричний ряд:

$u_{j}=\sum_{k} u_{j k} \exp (i \mathbf{k r})$

умовно назвавши члени цього ряду “статичними" коливаннями.

Підставивши вирази (39) та (40) у формулу (32), отримаємо суму доданків, кожен з яких відповідає взаємодії двох нормальних коливань та одного "статичного" коливання. Позначимо їх хвильові вектори через $\mathbf{k}^{\prime}, \mathbf{k}^{\prime \prime}, \mathbf{k}^{\prime \prime \prime}$, а частоти перших двох коливань - через $\omega^{\prime}, \omega^{\prime \prime}$. У формулі (32) передбачається підсумовування по r. Крім того, звичайно мають справу з енергією, усередненою за часом. Отже, кожен із згаданих доданків при розрахунку енергії необхідно проінтегрувати по $t$ та підсумувати по $\mathbf{r}$.

З класичної теорії твердого тіла [5] відомо, що після виконання таких операцій кожен із згаданих доданків 
буде суттєво відрізнятись від нуля лише тоді, коли будуть виконані дві умови:

$\mathbf{k}^{\prime}+\mathbf{k}^{\prime \prime \prime}-\mathbf{k}^{\prime \prime}=0$

$\omega^{\prime}+\omega^{\prime \prime}=0$

Зрозуміло, що за таких умов ні про який обмін енергією між тепловими коливаннями не може йти мови, а отже, запропонований механізм ніби не може забезпечити встановлення максвеллівського розподілу.

Однак класична теорія розглядає коливання, що поширюються в ідеальній гратці. Це - делокалізовані коливання. В нашому ж випадку йдеться про коливання, які локалізовані в області із розміром $\Delta r$. Тому хвильове число може бути визначене лише з похибкою $\sim \pi / \Delta r$, і відповідно частота - із похибкою $\sim \pi c / \Delta r$. При цьому рівності $(41),(42)$ замінюються нерівностями

$\left|\mathbf{k}^{\prime}+\mathbf{k}^{\prime \prime \prime}-\mathbf{k}^{\prime \prime}\right|<\pi / \Delta r$

$\left|\omega^{\prime}+\omega^{\prime \prime}\right|<\pi c / \Delta r$

Згідно із виразом (44) два нормальних теплових коливання взаємодіють, якщо різниця їх частот менша за $\pi c / \Delta r$. Тепер, якщо згадати, що хвильове число змінюється порціями $\pi / L$, і відповідно частота - порціями $\pi c / L$, то виявиться, що на частотному проміжку $\pi c / \Delta r$ розташовується значна кількість частот. Саме взаємодія теплових коливань, що мають такі частоти, і забезпечує встановлення максвеллівського розподілу.

"Статичні" коливання, хоча безпосередньо і не беруть участі в обміні енергією, як це видно із виразу (44), все ж відіграють важливу роль у встановленні локального максвеллівського розподілу. Саме завдяки "статичним" коливанням досягається локалізація теплових коливань: останні локалізуються внаслідок розсіяння на перших. Певний внесок у розсіяння теплових коливань вносять також процеси, що визначаються доданками першого порядку по $\mathbf{W}$ iз суми (30).

Відповідно величина $\Delta r$ фактично є довжиною $l_{1}$ затухання теплових коливань, викликаного згаданим розсіянням. В цьому можна переконатись хоча б із таких наближених оцінок.

Грубо кажучи, "статичні" зміщення частинок від положень рівноваги можна розглядати як появу в структурі кристала дефектів. Ці дефекти являють собою перешкоди для теплових хвиль. Переріз розсіяння $\sigma$ такої перешкоди можна грубо оцінити співвідношенням $\sigma \sim u^{2}$. Концентрація перешкод $n$ має порядок $n \sim 1 / a^{3}$. Визначаючи довжину затухання виразом $l_{1} \sim 1 / n \sigma$ і підставляючи в цей вираз значення $n$ та $\sigma$, приходимо до формули $(20)$.

Після локалізацї високочастотних коливань їх уже не відрізнити одне від одного, якщо різниця їх частот $\Delta \omega$ менша за $\pi c / \Delta r$ - ця різниця стає для вказаних коливань масштабом частоти. Відповідно масштабом хвильового числа для них стає величина $\pi / \Delta r$.

Всього областей розміром $\Delta r$ в системі нараховується $(L / \Delta r)^{3}$. Коливання, локалізовані в одній області, не взаємодіють із коливаннями, локалізованими в інших областях. Отже, високочастотні коливання $\epsilon$ виродженими, а їх ступінь виродження становить $(L / \Delta r)^{3}$.

Задля визначеності конкретизуємо нерівність (37), переписавши їі, наприклад, у вигляді виразу

$k \Delta r \geqslant 10$

i тим самим, увівши нижню межу $k_{m}=10 \pi / \Delta r$ для хвильового числа локалізованих коливань. Частота такого коливання дорівнює $\omega_{m}=10 \pi / \Delta t$. Якщо врахувати отриману раніше числову оцінку для $\Delta t$, то виражена в $\mathrm{cm}^{-1}$ згадана частота становить величину порядка десяти $\mathrm{cm}^{-1}$. Виявлення смуг поглинання в цій області КР-спектрів рідини служитиме свідченням реальності локалізованих коливань і, водночас, дасть можливість визначати характеристики ФМНО для рідин із експерименту.

\section{7. Висновки}

1. У рідині високочастотні теплові коливання локалізуються внаслідок розсіяння на флуктуаціях рівноважних положень частинок. Розмір областей локалізації приблизно дорівнює довжині затухання згаданих коливань і має порядок ста нанометрів. Локалізовані коливання можуть спричинити появу в спектрі комбінаційного розсіяння смуг поглинання, що відповідають частотам порядку десяти обернених сантиметрів.

2. Локальний максвеллівський розподіл в рідині встановлюється завдяки взаємодії між локалізованими коливаннями. Відповідно областю, де існує цей розподіл є область локалізації цих коливань, а часом встановлення розподілу - час, за який встановлюється те- 
плова рівновага в системі згаданих коливань. За порядком величини цей час дорівнює $10^{-10} \mathrm{c}$.

1. Л.Д. Ландау, Е.М. Лифшиц, Гидродинамика (Наука, Москва, 1988).

2. Ю.Л. Климонтович, Статистическая физика (Наука, Москва, 1982).

3. Ф.М. Куни, Статистическая физика и термодинамика (Наука, Москва, 1981).

4. Я.И. Френкель, Кинетическая теория жидкостей (Наука, Москва, 1980).

5. А.С. Давыдов, Теория твердого тела (Наука, Москва, 1976).

Одержано 29.03.12

\section{ЛОКАЛЬНОЕ МАКСВЕЛЛОВСКОЕ РАСПРЕДЕЛЕНИЕ В ЖИДКОСТЯХ}

Л.А. Булавин, Ю.Ф. Забашта

Р е з ю м е

Рассмотрены пространственный и временной интервалы, которые служат для жидкостей масштабами в гидродинамике. Эти интервалы отождествляются с размером области, в кото- рой устанавливается локальное максвелловское распределение, и временем, за которое это распределение устанавливается. Показано, что максвелловское распределение возникает в жидкостях благодаря взаимодействию между локализованными тепловыми колебаниями частиц жидкости. Для пространственного и временного масштабов гидродинамики получены оценки - соответственно, 100 нм и $10^{-10}$ с.

\section{LOCAL MAXWELLIAN DISTRIBUTION IN FLUIDS}

\section{L.A. Bulavin, Yu.F. Zabashta}

Taras Shevchenko National University of Kyiv, Faculty of Physics (64, Volodymyrs'ka Str., Kyiv 01601, Ukraine;

e-mail: zabashta@mail.univ.kiev.ua)

$\mathrm{S}$ u m m a r y

The spatial and temporal intervals playing the role of hydrodynamic scales for fluids have been analyzed. Those intervals are identified with the dimensions of a region, in which the local Maxwellian distribution is established, and a time interval, for which this distribution is established. The Maxwellian distribution is shown to arise in fluids owing to the interaction between the localized thermal vibrations of fluid particles. For the spatial and temporal hydrodynamic scales, the estimates of $100 \mathrm{~nm}$ and $10^{-10} \mathrm{~s}$, respectively, are obtained. 